\title{
Recreational potential of metaphorization in mental self-regulation of the students
}

\author{
Olena Kostyuchenko
}

Kyiv National University of Culture and Arts, Kyiv, Ukraine

\begin{abstract}
Introduction: In the era of dynamic modern transformations in the education system, there is a need for effective psychological tools for updating individual psychological and life resources, self-regulation of students' mental states, contributing to the preservation and support of their mental health.
\end{abstract}

Purpose: to substantiate the recreational potential of the metaphorization of mental states as a recreational method of self-regulation in the system of psychological well-being, to identify its individual psychological characteristics in students.

Methodology: Experimental work was carried out on the basis of Kyiv National University of Culture and Arts, Tavriya National University named after V. Vernadsky. Five hundred and ten respondents were involved in the research process (18 - 45 years, 65\% female; study specializations: "Arts", "Design", "Management", "Psychology"). The research was based on the analysis of free associative experiment, method of cognitive interpretation, praximetric and executive methods for distributing certain semantic units

Results: the most popular among students causes of dissatisfaction in the situation with stress and lack of satisfaction in basic psychological needs, negative and positive conditions at different levels, life furnishings, those situations when there are stinks; on the basis of the experience of the SUM inquirer, there are positive changes in the most of the majority of students. On the basis of the developed model of self-regulation of mental states by means of metaphorization (5 stages of the act of metaphorical creativity of resource states), when its recreational functions are realized, transformations of strategies of thinking and life take place, internal resources are activated

Conclusions: The developed model of metaphorization of search of resource states is an effective means of stabilization and self-regulation of a mental condition of students that allows to be guided quickly in changing living and educational conditions, to choose optimum for each separate case methods and means of mental self-regulation

\section{Keywords}

mental health, psychological well-being, mental state, individual psychological resources, mental self-regulation, recreational potential, metaphorization.

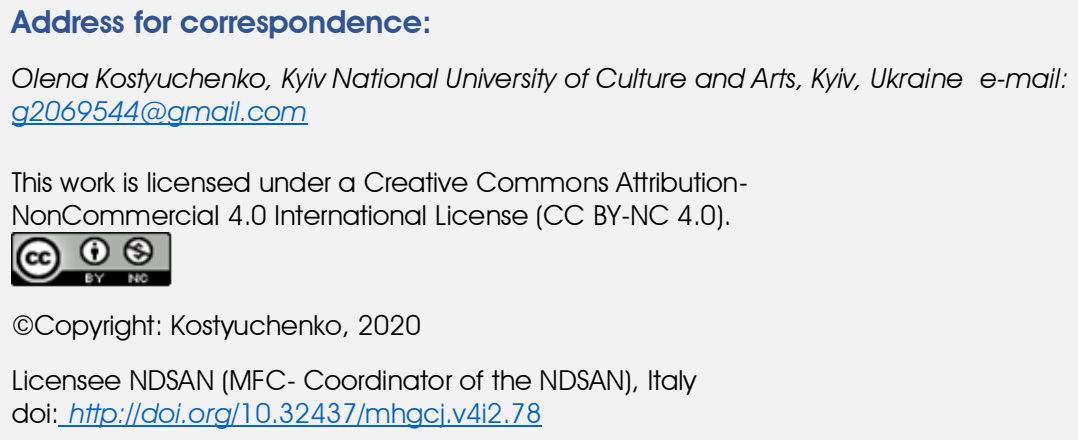

Submitted for publication: 27 June 2020

Received: 27 June 2020 Accepted for publication: 8 September 2020 


\section{Introduction}

The variety of challenges which surrounding the reality in all spheres of young people's lives is characterized by high mental pressure, chronic fatigue, increased anxiety, emotional and informational stress, and other etiological factors. In the majority of cases, these factors cause strain, asthenization of adaptation mechanisms, and an exhaustion of the body's functional reserves lessening the efficiency and activity of a person. The most vulnerable group is the student youth in an era of accelerated modern transformations of the educational system. The development, normalization, and integration of the worldview are intrinsic characteristics of the students. Moreover, that process occurs on the background of emotional experiences associated with a significant number of crucial decisions made in the shortest periods.

A fundamental issue for our study is to describe such categories as "mental health", "psychological well-being", "mental states", "mental self-regulation", "individual psychological resources" in their relationship and interdependence. According to the principles of the axiological approach, mental health is seen as a social value that occupies a prominent place in the individual value hierarchy and correlates with value orientations. It is known that mental health is defined as a state of mental well-being characterized by the absence of painful mental manifestations. Thus, it maintains adequate regulation of behavior and activities in accordance with the circumstances of the surrounding reality. In the context of our study, among the many definitions of well-being by psychologists, have identified the following: particularly on the basis of the integrity in defining true "Self", through a harmony of the mental processes and functions, when a person is aware of his integrity having inner balance; he is satisfied with himself and with the world around him, and reveals an ability to respond to existential challenges of life, including self-realization and personal growth (Ryff, 1989); the ability to move from reliance on the environment and manipulation of the environment to reliance on self and self-regulation (Perls et al., 1995); an affective state of emotional well-being, on the one hand, and a cognitive state of life satisfaction and of life's meaning, on the other hand (Emmons, 2004); a complex mental education, which is manifested in the experience of meaningful content and value of life, a sense of satisfaction with life and self, achieving current motives and needs of the individual in the perspective of socially significant goals and a positive assessment of their own existence (Karhina, 2018: 204).

According to these definitions, as well as other studies (Ryan \& Deci, 2001), it turns out to a large extent, the young person's psychological wellbeing is influenced by the level of formation of the self-regulation system. Based on the analysis of the diverse definitions of the concept of "mental self-regulation" (Novodvorskij, 2019), in the context of our research we will define it as one of the levels functioning for the regulation of the living systems activity, which is characterized by the use of mental means of reflection and modeling of reality (Meshcheryakov \& Zinchenko, 2003). Grimak states that mental self-regulation is "mental self-action for the purposeful regulation of the comprehensive activity of the body, its processes, reactions, and conditions" (Grimak et al., 1983: 151). Alekseev argues that mental selfregulation is "the influence of a person on himself with the help of words and corresponding mental images" (Alekseev, 1976, 3). Prokhorov refers to mental self-regulation as a three-level hierarchical organization, which is based on the mechanisms of regulation of a particular mental state (Prokhorov, 2017). Mental self-regulation of a person includes behavior or activity control and self-regulation of his present state (Leonova \& Kuznetsova, 2009; Konopkin, 1980; Morosanova, 2010). Common to all definitions is focus on a person's state as an object of influence and tendency to use internal means of regulation, primarily - the mechanisms of psychological selfinfluence. Self-regulation in everyday life is associated with the personal position in the adaptation process (Hartmann, 2002), as well as with the harmonization of the functional systems of the body and psyche, with the tendency for a balance, and for reducing a disbalance of functional connections (Bodrov, 2007), with the solution of problems (Dikaya, 2003), with deliberate self-regulation (Konopkin, 2007; Morosanova et al., 2017, 2018; Bondarenko ef al., 2020), with behavior control (Sergienko, 2009; Pulkkinen, 1992; Posner, Rothbart, 2000), with the formation of regulatory experience (Osnitsky, 2011), successful behavior management (Rasskazova, 2019) and others.

This requires the use of effective psychological tools and realization of psychological and vital resources of individuals that help to preserve and support the mental health, assist in adaptation to the objective conditions along with adequate responses to the external influences plus provide the regulation and stability of behavior and activity. 
Traditional psychological resources are considered in connection with the studies of the constructive basis of personality. Such studies are carried out in the framework of the humanistic perspective in psychology. Psychological resources are a complex structure. They are integrated with the major part of the mental health system and human self-sufficiency. The part of the study is focused on the mechanism of psychological coping (coping behavior) development. Thus, personal characteristics such as psychological, professional, and physical are disclosed that either help in managing extreme life situations or prevent the individual to cope with them.

Search for psychological resources presupposes using all possible environmental ways and various psychological tools, one of which is the metaphorization of resource mental states. It is a dynamic process of applying personal life strategies of thinking without restrictive filters, which helps to increase the level of self-awareness and self-recognition of deep inner mental tendencies, thus, influencing the states, decisions, actions, behavior, as well as a feeling of happiness and well-being. Also, reliance on these resources is a key point in selfregulation, and as a rule, they expand the opportunities. If a person is convinced of his abilities to control a situation, then he is ready to act effectively and overcome difficulties. If these convictions have remained unshakable in the extreme conditions of reality it would be sufficient for a person to rely on these psychological resources.

\section{Purpose}

The purpose of the paper is to substantiate the recreational potential of the metaphorization of mental states as a recreational method of selfregulation in the system of psychological wellbeing, to identify its individual psychological characteristics in students.

\section{Methodology}

\section{Design}

This research makes use of a qualitative research strategy (Silverman, 2004), where the connection between several different variables had to be established through interpretation. The Research Approach implemented has been that of interpretivism (Willis, 2007). Also, the research makes use of semantic and cognitive direction of psycholinguistics (E. Kubryakova,A. Babushkin, N.
Boldyrev, E. Lukashevich, Z. Popova, I. Sternin, etc.).

The scientific and psychological principles of mental health form the theoretical and methodological basis of this research. The mental health is an integrated characteristic of an individual, which is associated with his inner world (B. Bratus, S. Maksymenko, A. Maslow, Yu. Yashchyshyna, etc.). Also, the scientific and psychological principles of additional aspects of mental health set up the theoretical and methodological foundation of this study. They are following: the state of health determinant factors (V. Ananiev, S. Grombach, I. Dubrovina, V. Kaznacheev, G. Ushakov, and others); the psychological support of mental and physical health (M. Korolchuk, V. Krainyuk, A. Kosenko, T. Kochergina, and others); the psychology of human health (G. Lozhkin, O. Noskova, $G$. Nikiforov, I. Tolkunova, and others), the mental states (W. Wundt, W. James, P. Janet, J. Kettel, N. Levitov, V. Myasishchev, B. Parigin, S. Rubinstein, $H$. Selye and others), types of self-regulation of the personality, in particular cognitive, emotional, volitional, and personal types, which constitute a single structure of mental self-regulation of the personality (K. Abulkhanova-Slavska, V. Selivanov, O. Polshin, Y. Alexandrov, etc.). The metaphor as the multi-faceted phenomenon has gained recognition in the publications of $\mathrm{K}$. Alekseev, I. Vachkov, V. Gak, D. Guilford, D. Davidson, J. Lakoff, E. McCormack, V. Moskalyuk, S. Neretina, J. Ortega-and-Gasset, I. Polozova, O. Potebna, and others.

\section{Methods}

In this research, we used different kinds of methods such as theoretical: analysis, synthesis, generalization; empirical: free associative experiment plus content and intent analysis, method of cognitive interpretation, praximetric and executive methods for distributing certain semantic units of the content and textual information into thematic groups, which allowed to identify status notifications, namely, their typical emotional, and psychological characteristics; statistical: quantitativepercentage ratios, identification of the hierarchical order based on the frequency of reactions to verbal and visual stimuli; interpretive: structural method.

\section{Experimental base of research}

Experimental work was carried out on the basis of Kyiv National University of Culture and Arts, Kyiv University of Culture and Arts, Tavriya National University named after $\mathrm{V}$. Vernadsky, in total, 510 respondents were involved in the research process, including students of $2 \mathrm{nd}$, 3rd, 5th 
courses specialties directly "Arts", "Design", "Management", "Psychology" (from 18 to 45 years, average age was 22; 65\% female).

Organization and stages of psychological research:

1) substantiation of the recreational potential of the metaphorization of mental states - one of the criteria for mental health; 2) a theoretical analysis of the problem of the applicability of the metaphorization of mental states in their selfregulation, the level of which affects psychological well-being in the mental health system; 3) development and testing of a theoretical and methodological model of selfregulation through metaphorization of psychological representations of the image of real, actual and optimal states in students (executive method (Schwantsara, 1978)): students' performance of creative tasks: choose metaphorical images associated with real and resource states; compare them characteristics; based on the interpretation of images and the open-ended questions developed by the author (the questionnaire), describe the possibilities of transformation and self-regulation of states; students' self-assessment of the psychoemotional state using the SAM inquirer (state of health-activity-mood) (Doskin V.A. et al., 1973) "Test of differentiated self-assessment of the functional state" (before and after performing creative tasks); 4) on the basis of an associative experiment, content and intent analysis, the allocation of certain semantic units of content and textual form of information into thematic groups, which made it possible to identify characteristic emotional and psychological characteristics of the message about states; on the basis of cognitive interpretation, the identification and verbal formulation of "cognitive features, represented by certain meanings or semantic components of linguistic units" (Popova \& Sternin, 2007: 141); 5) the analysis of the results of the questionnaire (praxeometric method (Ananiev, 1996)) was carried out through manual thematic analysis, where the author sought to find common words, phrases and group or "combine" them together in order to be able to determine trends in the respondents' answers. The results of the questionnaires were presented in the format of tables and diagrams for determining percentages, a hierarchy of the frequency of reactions to verbal and visual incentives.

\section{Ethical Considerations:}

1) participation in the research is voluntary; 2) the respondents were informed in advance about how the research results will be used and about their availability to those who are interested in them; 3) all the information collected in the course of this dissertation has been used only for the purposes of the study, and will be kept confidential.

\section{Results}

Problems of health, well-being, and adaptation are solved by certain tools of awareness of personal potentials, and desires, also through the effective management of his states and thinking, and the whole personal life (Kostyuchenko O., 2019c). For example, imagogics is the analysis of spontaneous images for gaining access into "in-se" (Ontopsychological School, A. Meneghetti). Another example is awareness and control of "maladaptive thoughts" that are incompatible with the ability to "cope with life", and remain the main cause of maladaptive states, and disorders of inner harmony (cognitively oriented approaches, Albert Ellis, A. Beck, L. Festinger, and others). Another illustration is a personal perception and attitude changes towards events, and reactions. As a result, these changes reduce stress, balance thoughts, and beliefs including identity and spirituality, environment, and behavior (neurolinguistic programming, R. Bandler, and J. Grunder). "Recapitulation of personal history" is the key to recollecting. Recollecting means remembering or reassembling in memory as well as coming to your senses, regaining consciousness, and reconstructing. The usage of internal resources is one of the practices among shamans in North America, which is described in the book called "A Power of Silence" (Carlos Castaneda, 1987). The essence of the procedure is to gradually review the events of person's life starting with thinking, remembering the most important events, "taking" useful resources from personal past, namely, knowledge, strategies, states, and "giving away" all experiences that hold a person in the past. Every person has many resources in personal experience that will help him to cope with any situation in the future. The main tasks are summarized as following: getting access to resources of personal past, acting and achieving goals now based on the personal dreams, seeing new opportunities for selfrealization, designing personal interesting future and preparing the way for it, and fill the life with meaning. With resources, you can take care of the improvement of psychological health, you can (Titarenko, 2018: 148) ability: up to the renewal of the intrinsic integrity, vibrating new life prospects; to the intensive and sensible joke of 
specialness as an energetic engine of change; to the most effective and other.

The concept of "Resources" is understood (Leontiev, 2016: 22) as a means, the presence and sufficiency of which contributes to achieving the goal and maintaining well-being, and the absence or insufficiency - makes it difficult. Among the psychological or personal resources are motivational, instrumental, psychological resources of stability and self-regulation. Psychological resources of self-regulation include psychological variables that reflect stable but selected from a number of alternatives strategies of self-regulation as a way to build dynamic interaction with life circumstances, such as a measure of subjective control over them or dependence on them, stable expectations of positive or negative outcomes of events, strategies of interaction with complexity and uncertainty, flexibility or rigidity of goal setting, etc. (Leontiev, 2016: 23).

On the one hand, we hold that recreation is a process and a method of recreating a person in physical, mental, cultural, and spiritual aspects. On the other hand, recreation is also associated with the realization of potentials, and essential forces of personality, namely, the desire of the individual to recreate the self to the level of ideal, holistic "I-image", It consists of the following components: rational-cognitive (personal experience, theoretical ideas); emotional-sensory (emotional response to the manifestations of personal self); sensory-perceptual (adequate perception of body signals, which are formed on the basis of "body scheme" and supplemented by audio, visual and other signals); motivational (the need to be a creative person, a measure of responsibility, readiness for a creative activity for the benefit of personal spiritual, mental, and physical health) (Kostyuchenko, 2019c). The formation of these components determines the individual qualities of self-regulation that are characterized by how a person plans and organizes goal achievement, takes into account significant external and internal conditions, evaluates the results and adjusts his activity for achieving subjectively acceptable outcomes (Morosanova, 2010). It secures psychological well-being.

Some authors emphasize such basic recreational tasks of diverse methods of mental self-regulation as relief the stress manifestations and enhancing resource mobilization. The activation of resource main features is focused on the formation of adequate internal tools that allow a person to change his state. The intention to change or regulate personal state becomes dominant. The same features are characterized by the awareness of the individual, psychological resources in the system of psychological wellbeing through metaphorization.

Metaphorization is one of the widely spread methods of figurative representation that refers to one or another denotative (conceptual) sphere. In the context of our study, it is individual psychological resources. The synthesis of theoretical data demonstrates that in home psychological researches the metaphorization is defined the most often as a specific kind of cognitive activity that operates and controls the metaphorical images thus creating new images that are full of meanings and they make meanings visible (Kostyuchenko, 2019a, b).

An "interaction of two cognitive structures of knowledge" occurs in the process of metaphorization. "There is the cognitive structure of the 'source' or 'source domain'. It is more specific knowledge obtained by a person in the process of direct experience during interacting with reality. Also, there is the cognitive structure of the 'target' or 'target domain'. It is less clear, less specific, and less defined knowledge". That kind of knowledge is called "knowledge by definition" (Baranov, 2003: 75; Samigullina, 2008: 54). Furthermore, the third element is involved in the metaphorization process, that is the image, and thus, it becomes possible to produce the socalled metaphorical projection. The image provides the fixed correlations (invariance) between the source domain and the target domain. The image is a basis for the structure of the metaphor, in other words, the image is a content that is invariantly present in both interactive areas. The image is formed in the process of metaphorical conceptualization of a certain fragment of reality that has already received primary conceptualization (Lakoff, 1990: 5). At the same time a metaphor likewise a predetermined template or cliché is understood not only as a result but also as a means of conceptualizing new experience for the metaphor uses previously acquired knowledge.

During the empirical study, the students were asked, for instance: 1) to choose both proposed and desirable metaphorical images which were associated with their real mental state in a quarantine situation plus with resource / optimal state, and describe them; 2) to compare the characteristics of images such as commonexcellent, pleasant-unpleasant, unexpected, positive-negative, and describe the possibilities for their transformation; 3) the students had to interpret the images and to respond on such questions as: "What is my mental state like?", 
"How can I describe my real mental state?", "What kinds of personal resources are needed for the optimal state?", "What kinds of realized and unrealized strong characteristics are functioning in the present mental state?", "How can I influence in the best manner possible on the harmonization of mental state?": "What will assist in the further regulation of personal state?", "What kinds of circumstances, situations, and conditions are resources for you?", "What will you do (3 specific steps) for renewal, restoration, and realization of resources?".

The analysis of student responses revealed that: 1) in a situation of stress and unmet basic psychological needs (stability, variety, significance, etc.) a young person subconsciously begins to look for the causes of dissatisfaction in the immediate environment. However, the real problem occurs because the access to the personal internal resources is closed, and expectations of the better mental state are unclear and vague when confusion and uncertainty prevailed. For example: "what I want to do, that I do not practice" or "what I do not want to do that I do", "I cannot see the future", "I don't know what I need ...", "... I don't understand how to live on further...", "... I'm at a dead end!", "stick in a space", "stick in the mire", "hit our heads against a stone wall", "we see the world through a glass darkly", "we engender starry-eyed goals", "in a state of suspense and confusion"; 2) changes occurred: generally some students experience apathy, anxiety, discomfort, and confusion but despite such personal problems the vast majority of the students felt deeply their need to restore healthy internal state including attentiveness, concentration, creativity, emotional stability and trust in their resources, efficiency, and ability to cope with the challenges of reality. Before the students expressed such thoughts as "we need to get through ..." or "just bide our time...", or "let us survive and then we'll see", but now they were sure that "it is necessary to strengthen inner courage and strength of spirit to maintain common sense and to resist to negativity, and to activate resources for restoring the stamina. . .etc.; 3) the most often the respondents identified such negative characteristics as uncertainty, apathy, disappointment, concern, laziness, helplessness, doubt, depression, fatigue, aggressiveness, anxiety, etc., and likewise positively colored mental state, for example, joy, happiness, liveliness, calmness, satisfaction, enthusiasm, inspiration, etc.; 4) the students often referred to the difficult life circumstances and situations resulting in negative mental states such as
Ioneliness, quarrel, family conflicts, lack of money, disharmony with loved ones, illness, separation, and failure. Also, some other equally stressful situations were mentioned, for instance, "I don't see my beloved ones for a long period", "when I am overloaded with drudgery", "when my plan goes wrong", etc. Similarly, the students point out on positive situations, for example: "spending time with a loved one", "completing any work", "meeting with a dear person", "successfully passing an exam", "achieving the desired", "being in a happy company", "having a mutual understanding"; "purchasing thing", "carrying out a plan", "having cash", "when the news is good", "when many friends visit my home", etc.; 5) the most respondents used the methods and techniques for self-regulation of both negative and positive states, for instance: communication, inner-quarantine, disassociationshifting, reasoning, relaxation andcreative activity; 6) the positive states on the sensory-perceptual level were associated with a feeling of vigor, and the ability to act, a capacity for intensive activity, and comfort; healthy well-being on the emotional and sensual level has been linked to such outcomes as excitement, experiencing joy from the creative process and its results, adequate positive self-esteem, and gratitude; the healthy mental states on the rationalcognitive level were characterized by a high degree of awareness and competence of self plus the knowledge of the criteria of "optimal self", and appropriate behavior including the main factors that promote or prevent creativity, and self-development along with awareness of selfhood and joyful surprise at the originality of others; the mental well-being on the motivational level resulted in a high level of internal motivation for a creative lifestyle, creative self-expression, the priority of psychological, mental, and physical health in the individual value system.

Let's pay attention to the peculiarities of psychodiagnostics research using the SAM inquirer (state of health-activity-mood), the advantage of which is the operative differentiated self-assessment of the functional state. One of the criteria of mental health is mental states (emotional balance, the maturity of feelings according to age, the ability to control the negative emotions, the free expression of feelings and emotions, and the ability to rejoice and to maintain normal optimal well-being). It is possible to study any type of subject's activity only based on these healthy mental states. The definition of the human condition is important in our study. Ilyin refers to the human condition as a holistic, systemic response to external and internal 
actions aimed at maintaining the integrity of the organism, and ensuring its viability in specific circumstances of living (llyin, 1978: 18). Thus, the mental state is the main mechanism in the restructuring of psychological properties and changes in mental processes as well as the organization of a qualitatively new psychological structure of the individual that is necessary for the effective functioning of the subject.

The diagnostic material of the "SAM" method consists of 30 pairs of definitions opposite in meaning; the respondent must in each pair choose the most appropriate definition for his condition and assess the severity of this aspect of his condition on a scale from 0 to 3 points. The technique includes 3 scales: well-being, activity, mood. Based on reliable results, the integral mental state indicator is calculated by finding the arithmetic mean. On the basis of self-assessment, students were asked to identify changes in states (both positive and negative). We focused on such indicators (active, effective, enthusiastic, full of hope, satisfied, attentive) (figure 1).

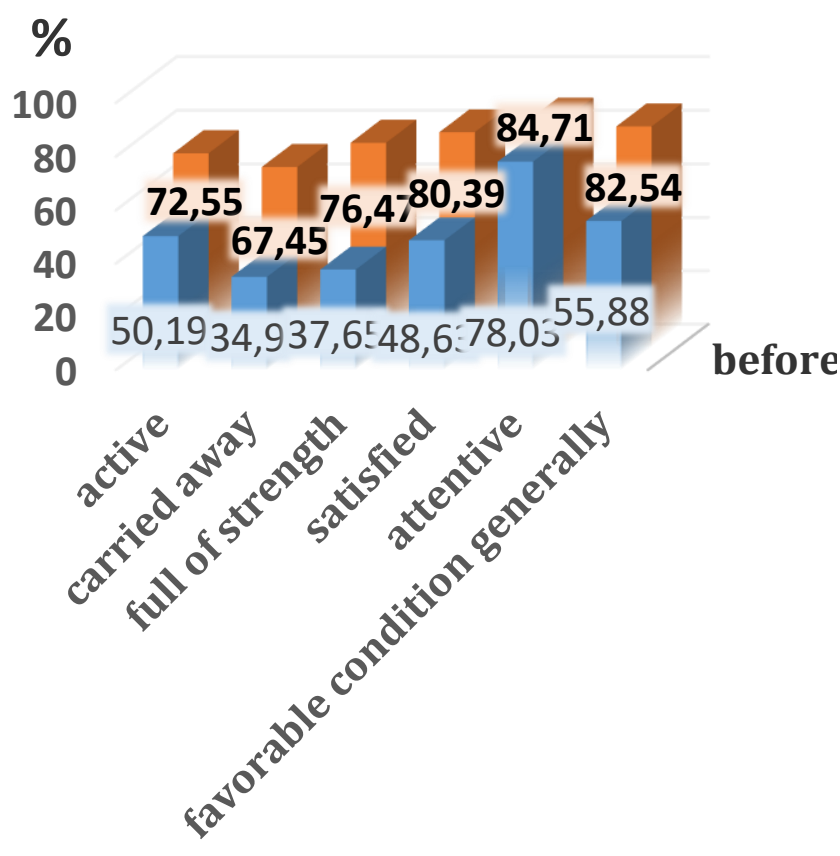

Figure 1. Dynamics of actualization of favorable functional states and their positive characteristics according to the "SAM" questionnaire among students (510 responses) before and after metaphorization of the image of the actual and resource state

As a result of comparing the data of selfassessment by the subjects of their states (before and after the research work), their predominant improvement in most indicators was revealed in $82.54 \%$.

\section{Discussion}

The theoretical analysis and empirical research conducted by us and other researchers (Kargina, 2018; Rasskazova, 2019; Balashov, 2020 and other) results confirmed the hypotheses and revealed that due to the application of the developed model of self-regulation of mental states by means of their metaphorization, namely the use of metaphorical images in visual and verbal form provides opportunities for awareness of the emotional, mental and physical spheres, psychological resources of one's own personality, the mobilization of internal reserves of the psyche, its potential. Metaphorization is defined as the interaction of two cognitive structures of knowledge: "source domain" and "target domain" with the participation of an image, due to which it becomes possible to implement the so-called metaphorical projection; as a specific type of mental activity, the content of which is the operation and manipulation of metaphorical images, and the result is the creation of new images, meaningfully filled and making meaning visible. Disclosure of the "metaphorical image" category is associated with such concepts as figurative code and figurative representations along with the functions of metaphorical images, for instance, cognitive, prognostic, regulatory, creative, and communicative which are recreational.

Thus, the process of metaphorization as an act of metaphorical creativity of resource states consisted of five stages: awareness: "What is happening now?"; turning point: "What I need to change?" and "What I do not want to change?"; modeling of the possible future: "What should I do?", "What is the price of the changes?"; steppingstone: "What does hold me back?", "What kinds of fears do exist?", "What is the price for the halt or the resistance?"; choice and forward movement: "What are the first steps on this path?", "What kinds of external and internal resources do I need for this?". As a result, thinking strategies have changed. The internal resources are activated, for instance, confidence, creativity, and energy, etc. The internal struggle ceased and is replaced by a sense of balance. Moreover, the life scenario is transformed offering new opportunities for success. 


\section{Limitations of the study}

The main problems that the researcher faced during the research: 1) limitation of time (academic hour) and the situation of online communication (in a cross-platform messenger Telegram that allows exchanging messages and media files of many formats); 2) the use of an interpretive approach, which was determined by the nature and goals of the study. In this sense, the results and achievements of this project can be considered biased, since the relationships between the various variables have been determined not on the basis of empirical evidence, but on the basis of the analytical and judgmental skills of the researcher, in the context of a particular academic field.

\section{Practical value}

Practical value of the results of our study can be used in solving scientific and practical problems aimed at increasing conscious selfregulation through metaphorization of current conditions and, thus, to preserve and maintain mental health, increase the effectiveness of educational and professional activities.

\section{Conclusions}

We hold that one of the effective approaches for maintaining mental health and preserving the healthy well-being of the student youth are the self-modeling of reality based on the development of mental state self-regulation. Selfmodeling is a holistic, adequate systemic response to the external and internal influences that aimed at maintaining the integrity of the body and ensuring its vital functions in the specific living conditions together with the stability of behavior. It includes the ability to maintain familiar comfortable well-being and to relieve stress manifestations, and to enhance resource mobilization.

We consider that the metaphorization of the search and recognition problem of individual psychological resources is one of the effective means of stabilization and self-regulation of the mental condition of the students. It is the universal methodological tool of the cognitive process for it allows you to be quickly navigated in the changing living and learning conditions. It assists you to choose such methods and means of mental self-regulation that are optimal for each situation. It is proved that the students, who used multidimensional, multifunctional and ambiguous metaphorical images, not only strengthened associations with their psychological resources, but also activated the volumetric and complete self-perception, plus identified the new opportunities in a holistic system of "I-others-world" that resulted in the realization of their creativity.

Further research on the problem can be directed to the study of individual-typical, gender, and age features of the metaphorization of the resource mental states.

\section{Conflict of interest}

The author declares that she has no conflict of interests.

\section{References}

Alekseev, A.V. (1976). On the adequacy of selfhypnosis formulas. Theoretical and applied research of mental self-regulation. Kazan: KSU Publishing House. [Published in Russian]

Ananiev, B.G. (1996). Psychology and problems of human science. Moscow: Institute of Practical Psychology; Voronezh: NPO MODEK. [Published in Russian]

Balashov, E.M. (2020). Features of style of selfregulated educational activity of students. Theoretical and applied problems of psychology. Severodonetsk: Proceedings of the Volodymyr Dahl East Ukrainian National Universityl (51), 5-15. [Published in Ukrainian]

Baranov, A.N. (2003). On the types of compatibility of metaphorical models. Questions of linguistics, 2, 73-95. [Published in Russian]

Bodrov, V.A. (2007). Psychological mechanisms of human adaptation. Psychology of adaptation and social environment: modern approaches, problems, prospects. Moscow: Institute of Psychology RAS, 42-67. [Published in Russian]

Bondarenko, I.N., Potanina, A.M. \& Morosanova, V.I. (2020). Conscious self-regulation as a resource for success in the Russian language in students with different levels of intelligence. Experimental psychology (Russia), 13 (1), 6378. [Published in Russian]

Dikaia, L.G. (2003). Mental self-regulation of a person's functional state. Moscow: Institute of Psychology RAS. [Published in Russian]

Dikaia, L.G., Semikin V.V. (1991). The regulatory role of the image of a functional state in extreme conditions of activity. Psychological journal, 12 (1), 55-65. [Published in Russian]

Doskin, V.A., Lavrentyeva, N.A., Miroshnikov, M.P. \& Sharay, V.B. (1973). Test of differentiated self-assessment of the functional state. 
Questions of psychology, 6, 141-145. [Published in Russian]

Emmons, R. (2004). The psychology of higher aspirations. Personality Motivation and Spirituality. Moscow: Sense. [Published in Russian]

Grimak, L.P., Zvonikov, V.M. \& Skrypnikov, A.I. (1983). Mental self-regulation in the activities of the human operator. Questions of cybernetics. Mental conditions and performance. Moscow: Publishing House of the Academy of Sciences of the USSR, Scientific Council on the Complex Problem of Cybernetics. [Published in Russian]

Hartmann, H. (2002). Ego psychology and the problem of adaptation. Moscow: Institute for General Humanitarian Research. [Published in Russian]

Ilyin, E.P. (1978). The theory of functional systems and psychophysiological conditions. Moscow: Nauka, 325-346. [Published in Russian]

Kargina N.V. (2018). Resources and factors of psychological well-being of the individual. Candidate's thesis. Odessa, State Institution "South Ukrainian National Pedagogical University named after K.D. Ushinsky". [Published in Ukrainian]

Konopkin, O.A. (1980). Psychological mechanisms of regulation of activity. Moscow: Science. [Published in Russian]

Konopkin, O.A. (2007). Mechanisms of conscious self-regulation of arbitrary activity of human activity. In the book: V.l. Morosanova (Ed.), Subject and personality in the psychology of self-regulation. Moscow: Psychological Institute of the Russian Academy of Education, 12-31. [Published in Russian]

Kostyuchenko, O.V. (2019a). Cognitive potential of metaphorization in perception of "I-image". Psychological accompaniment of personality development: collective monograph. LvivToruń: Liha-Pres,

$178-204$. https://doi.org/10.36059/978-966-397-137-

7/178-203. [Published in English]

Kostyuchenko, O.V. (2019b). Metaphorization is a psychologic resource of potentiality of future professional. International Journal of Education and Science (IJES), 2 (2), 50-51. https://doi.org/10.26697 / ijes.2019.2.35.

[Published in Ukrainian]

Kostyuchenko, O.V. (2019c). Recreational approach to realization of social work principles. Social and psychological problems of modern society: collective monograf. LvivTorun. Liha-Pres, 114-136. [Published in English]
Lakoff, G. (1990). The Invariance Hypothesis: Is Abstract Reason Based On Image-Schemas? Cognitive linguistics, 1 (1), 39-74.

Leonova, A.B. \& Kuznetsova, A.S. (2009). Psychological technologies of human state management. Moscow: Sense. [Published in Russian]

Leontiev D.A. (2016). Self-regulation, resources and personal potential. Siberian Psychological Journal, 62, 18-37. [Published in Russian]

Meshcheryakov, B.G. \& Zinchenko, V.P. (2003). Mental self-regulation. Great psychological dictionary. St. Petersburg. [Published in Russian]

Morosanova, V.I., Bondarenko, I.N., Fomina, T.G. \& Burmistrova-Savenkova, A.V. (2018) Selfregulation, personality factors, academic motivation and math achievement in middle and senior school: variations across grade level. The European Proceedings of Social and Behavioural Sciences EpSBS. XLIII, 401-410. [Published in Russian]

Morosanova, V.I. (2010). Self-regulation and individuality of a person. Moscow: Nauka, 8. [Published in Russian]

Morosanova, V.I., Fomina, T.G. \& Tsyganov, I.Yu. (2017). Conscious self-regulation and attitude to learning in achieving educational goals. Moscow: Nestor-History. [Published in Russian]

Novodvorskij, E.V. (2019). Mental self-regulation of man: analysis of the content of the concept in the domestic psychology. Living safety, physical education and sport: current state and prospects. Khabarovsk: Pacific State University, 255-259. [Published in Russian]

Osnitsky, A.K. (2011). The development of selfregulation as a condition for the success of professional self-determination and training. In the book: V.I. Morosanova (Ed.), Psychology of self-regulation in the twenty-first century. Moscow: Nestor-Istoriya, 304-314. [Published in Russian]

Perls, F. (2018). Inside and outside the landfill. St. Petersburg: Peter. [Published in Russian]

Popova Z.D. \& Sternin, I.A. (2007). Cognitive linguistics. Moscow: East-West. [Published in Russian]

Posner, M.I. \& Rothbart, M.K. (2000). Developing mechanisms of self-regulation. Development and psychopathology, 12(3), 427-441.

Prokhorov, A.O. (2017). Self-regulation of mental states in everyday, everyday life of a person. Psychological research, 10 (56), 7. http://psystudy.ru [Published in Russian]

Pulkkinen, L. (1992). Self-Control and Continuity from Childhood to Late Adolescence. LifeSpan Development and Behaviour, 4, 84-105. 
Rasskazova, E.l. (2019). Psychological selfregulation as factor of success in the management of own behavior in different life domains. Experimental psychology, 12 (3), 148-163. [Published in Russian]

Ryan, R. \& Deci, E. (2001). On Happiness and Human Potentials: A Review of Research on Hedonic and Eudaimonic Well-being. Annual Review of Psychology, 52, 141-166.

Ryff, C. (1989). Happiness is Everything, or is it? Explorations on the Meaning of Psychological Well-being. Journal of Personality and Social Psychology, 6 (57), 1069-1081.

Samigullina, A.S. (2008). Metaphor in Cognitive Semiotic Lighting: Monograph. Ufa: RIC of BashSU. [Published in Russian]

Sergienko, E.A. (2009). Behavior control: individual resources of subjective regulation.
Psychological research, 5 (7). http://psystudy.ru [Published in Russian]

Silverman, D., (2004). Qualitative Research: Theory, Method and Practice. 2nd ed. London: Sage Publication.

Schwantsara, J. (1978). Diagnostics of mental development. Prague: Avicenum. [Published in Russian]

Titarenko, T.M. (2018). Psychological health of the individual: means of self-help in the conditions of long-term trauma. National Academy of Pedagogical Sciences of Ukraine, Institute of Social and Political Psychology. Kropynnytskyi: Imex-LTD. [Published in Ukrainian]

Willis, J.W., (2007). Foundations of Qualitative Research: Interpretive and Critical Approaches. London: Sage 